Revista Destaques Acadêmicos, Lajeado, v. 9, n. 3, 2017. ISSN 2176-3070 DOI: http://dx.doi.org/10.22410/issn.2176-3070.v9i3a2017.1487 www.univates.br/revistas

\title{
PESQUISA DE COLIFORMES TOTAIS EM ALIMENTOS COMERCIALIZADOS NO MUNICÍPIO DE JI-PARANÁ, RONDÔNIA
}

\author{
Tiago Barcelos Valiatti ${ }^{1}$, Izabel Bárbara Barcelos ${ }^{2}$, \\ Estela Nathana Mendonça Sanches², Deise Kelly da Silva², \\ Gabrielle Melo Calegari ${ }^{3}$, Fernanda Karen Virgolino de Almeida ${ }^{3}$, \\ Priscila Ferreira Lima dos Prazeres ${ }^{4}$, Wilker Moura Costa Silva ${ }^{4}$, \\ Natália Faria Romão ${ }^{5}$, Fabiana de Oliveira Solla Sobral ${ }^{6}$
}

Resumo: A carne moída, o leite e seus derivados são alimentos que possuem características propícias para a proliferação de microrganismos, portanto se faz necessária a avaliação das condições higiênico-sanitárias desses alimentos, e o grupo de microrganismos indicadores frequentemente analisados são os coliformes totais. $\mathrm{O}$ objetivo desse trabalho foi avaliar a qualidade microbiológica de amostras de carne bovina moída, de leite cru e pasteurizado e de queijo tipo minas frescal comercializados no município de Ji-Paraná, Rondônia, por meio da análise de coliformes totais. Foram analisadas 20 amostras de carne moída de 2 supermercados, 8 amostras de leite cru, e 8 de pasteurizado, além de 15 amostras de queijo minas frescal, sendo 5 com inspeção federal, 5 com inspeção estadual e 5 sem inspeção. Os resultados encontrados para as amostras de carne moída variaram de $<1,0 \times 10^{1}$ a $5,4 \times 10^{3} \mathrm{UFC} / \mathrm{g}$ de alimento, sendo

1 Farmacêuticos graduados pelo Centro Universitário Luterano de Ji - Paraná, Ji - Paraná, Rondônia.

2 Biomédicas graduadas pelo Centro Universitário Luterano de Ji - Paraná, Ji - Paraná, Rondônia.

3 Discentes do curso de Biomedicina do Centro Universitário Luterano de Ji - Paraná, Ji - Paraná, Rondônia.

4 Discentes do curso de Farmácia do Centro Universitário Luterano de Ji - Paraná, Ji - Paraná, Rondônia.

5 Bióloga, Mestre, Docente do curso de Ciências Biológicas do Centro Universitário Luterano de Ji - Paraná, Ji - Paraná, Rondônia.

6 Biomédica, Mestre, Docente do curso de Biomedicina do Centro Universitário Luterano de Ji - Paraná, Ji - Paraná, Rondônia. 
que o supermercado 1 apresentou maior contaminação. Com relação às amostras de leite, verificou-se, que o leite cru refrigerado e o pasteurizado apresentaram resultados dentro dos padrões estabelecidos. Já o leite cru não refrigerado apresentou altas contagens. Os queijos analisados demonstraram presença de coliformes totais em todas as amostras, porém somente aquelas sem nenhum tipo de fiscalização estavam com valores acima do recomendado. Os resultados encontrados verificaram baixa qualidade higiênico-sanitária nas amostras de carne, leite cru não refrigerado e queijo minas frescal produzido sem nenhum tipo de inspeção.

Palavras chave: Carne. Leite. Derivados. Rondônia. Alimentos de origem animal.

\section{INTRODUÇÃO}

Dados recentes evidenciam que o Brasil tem atingido bons resultados na produção de carne bovina e leite, o que o coloca entre os grandes produtores (IBGE, 2017). A carne bovina possui excelentes qualidades nutricionais, sendo fonte de proteínas, vitaminas e minerais (FAO, 2009; OLIVEIRA et al., 2008). Devido a essa composição rica em nutrientes, bem como elevada atividade de água e um $\mathrm{pH}$ favorável ao desenvolvimento de microrganismos, este alimento se caracteriza como um excelente meio de cultura para o desenvolvimento microbiano, podendo disseminar microrganismos patogênicos ao homem (MATOS et al., 2012).

A contaminação pode ocorrer desde a sangria, passando por toda tecnologia do abate, bem como no transporte, e nos pontos de comercialização, onde se destacam as práticas incorretas de manipulação (ALMEIDA et al., 2010). Quando moída, a carne oferece um maior risco de contaminação, uma vez que possui maior superfície de contato e sofre maior manipulação (MARCHI, 2006).

O leite é outro alimento de grande importância nutricional, sendo Rondônia o maior produtor de leite da região norte, destacando-se o município de Ji-Paraná, o qual abriga 47,08\% do rebanho leiteiro do estado (IBGE, 2011), possuindo uma tendência natural para pecuária, sobretudo leiteira, sendo o leite a principal fonte de renda dos produtores de base familiar (MAIA et al., 2010). No Brasil, esse alimento geralmente é obtido mediante condições higiênicas inadequadas, levando a quantidades elevadas de microrganismos, podendo a contaminação ocorrer por meio de diferentes fontes: dentro da glândula mamária, na superfície do úbere e tetos e na superfície de equipamentos e utensílios de ordenha e tanque (SANTOS; FONSECA, 2001).

Dentre os produtos derivados do leite, mais consumidos pela população brasileira, destaca-se o queijo minas frescal (VIEIRA et al., 2008). O qual possui como característica a massa crua, alto teor de umidade, não maturado, produzido mediante técnica simples, o que reflete em um baixo preço (PERRY, 2004). Estudos têm evidenciado que queijos do tipo minas frescal comercializados no Brasil são largamente contaminados, devido à utilização de matéria-prima inadequada, bem como locais de preparo e transporte com baixas condições de higiene (PERRY, 2004; ROCHA et al., 2006). 
Um dos principais grupos de microrganismos indicadores de qualidade microbiológica em alimentos e bebidas é o dos coliformes totais, considerado como importante indicador das condições higiênico-sanitárias (CARVALHO et al., 2008). Os métodos rápidos têm sido desenvolvidos para encurtar o tempo entre a coleta da amostra e a obtenção do resultado. O sistema Petrifilm ${ }^{\mathrm{TM}}$ é uma alternativa mais rápida ao método de plaqueamento convencional (GEUS; LIMA, 2006).

Diante do exposto, o objetivo do presente estudo foi avaliar a qualidade microbiológica de amostras de carne bovina moída, de leite cru e pasteurizado e de queijo tipo minas frescal comercializados no município de Ji-Paraná, Rondônia, por meio da análise de coliformes totais.

\section{METODOLOGIA}

Foram coletadas um total de 20 amostras de carne bovina moída, provenientes de dois supermercados, sendo 10 amostras de cada estabelecimento. Com relação ao leite, selecionou-se duas propriedades rurais para coleta do leite cru e dois estabelecimentos comerciais para coleta do leite pasteurizado, sendo que em cada local coletou-se quatro amostras, obtendo um total de 16 amostras. O leite cru da propriedade um encontrava-se armazenado em tanque de refrigeração, enquanto o da propriedade dois encontrava-se em tambor, sem refrigeração. Quanto ao queijo minas frescal, foram analisados três grupos, 5 amostras com inspeção Federal, 5 com inspeção Estadual e 5 sem inspeção, perfazendo um total de 15 amostras.

Após realizar a coleta, as amostras foram encaminhadas para o laboratório de microbiologia do Centro Universitário Luterano de Ji - Paraná, para posterior verificação da presença e quantificação de coliformes totais.

Para as análises, pesou-se $25 \mathrm{~g}$ do produto em saco estéril adicionando em seguida $225 \mathrm{~mL}$ de água peptonada $0,1 \%$, e homogeneizando por 3 minutos, constituindo-se, portanto, a diluição $10^{-1}$, sendo que a partir desta realizou-se as diluições seriadas pré-estabelecidas para cada alimento analisado (SILVA et al., 2010), onde, $1 \mathrm{ml}$ das mesmas foram inoculadas em placas $3 \mathrm{M}^{\mathrm{TM}}$ Petrifilm ${ }^{\mathrm{TM}}$ Coliform Count Plates $\mathrm{AOAC}^{\circledR}$ Official Method ${ }^{\mathrm{SM}} 989.10$, por $24 \mathrm{~h}$ a $35^{\circ} \mathrm{C}$, realizando posteriormente a leitura dos resultados. Ressalta-se que as análises foram efetuadas em triplicatas.

\section{RESULTADOS}

Conforme demonstrado na Tabela 1, dentre as amostras do supermercado um, as amostras $\mathrm{n}^{\circ} 4$ e 5 foram as que apresentaram maior quantidade de coliformes totais, já com relação ao supermercado dois, os maiores níveis de contaminação foi das amostras de $n^{\circ} 4,6$ e 8 . 
Tabela 1: Contagem de coliformes totais em amostras de carne bovina moída comercializada em dois supermercados do município de Ji-Paraná, Rondônia

\begin{tabular}{|c|c|c|c|c|c|}
\hline & Amostra & $\begin{array}{c}\text { Contagem de } \\
\text { coliformes totais } \\
(\mathrm{UFC} / \mathrm{g})\end{array}$ & & Amostra & $\begin{array}{c}\text { Contagem de } \\
\text { coliformes totais } \\
(\mathrm{UFC} / \mathrm{g})\end{array}$ \\
\hline \multirow{10}{*}{ 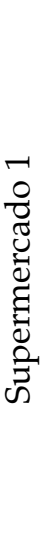 } & 1 & $1,5 \times 10^{2}$ & \multirow{10}{*}{ 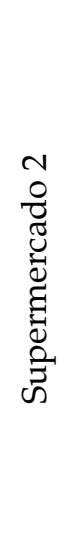 } & 1 & $<1,0 \times 10^{1}$ est. $^{*}$ \\
\hline & 2 & $1,6 \times 10^{2}$ & & 2 & $<1,0 \times 10^{1}$ est. $^{*}$ \\
\hline & 3 & $1,3 \times 10^{2}$ & & 3 & $2,4 \times 10^{2}$ \\
\hline & 4 & $3,6 \times 10^{3}$ & & 4 & $3,6 \times 10^{3}$ \\
\hline & 5 & $5,4 \times 10^{3}$ & & 5 & $6,9 \times 10^{2}$ \\
\hline & 6 & $4,0 \times 10^{2}$ & & 6 & $1,3 \times 10^{3}$ \\
\hline & 7 & $8,8 \times 10^{2}$ & & 7 & $8,7 \times 10^{2}$ \\
\hline & 8 & $1,0 \times 10^{2}$ & & 8 & $1,4 \times 10^{3}$ \\
\hline & 9 & $2,6 \times 10^{2}$ & & 9 & $3,1 \times 10^{2}$ \\
\hline & 10 & $1,7 \times 10^{2}$ & & 10 & $1,5 \times 10^{2}$ \\
\hline
\end{tabular}

Fonte: Dados da pesquisa.

A tabela 2 apresenta os resultados de contaminação por coliformes totais obtidos pelas análises das amostras de leite cru, onde é possível verificar que as amostras coletadas da propriedade dois foram as que demonstraram maior nível de contaminação.

Tabela 2. Contagem de coliformes totais em amostras de leite cru de duas propriedades rurais localizadas em Ji-Paraná, Rondônia

\begin{tabular}{c|c|c|c|c}
\hline $\begin{array}{c}\text { Propriedade } \\
\text { Rural }\end{array}$ & $\begin{array}{c}\text { Amostra 1 } \\
(\mathrm{UFC} / \mathrm{mL})\end{array}$ & $\begin{array}{c}\text { Amostra 2 } \\
(\mathrm{UFC} / \mathrm{mL})\end{array}$ & $\begin{array}{c}\text { Amostra 3 } \\
(\mathrm{UFC} / \mathrm{mL})\end{array}$ & $\begin{array}{c}\text { Amostra 4 } \\
(\mathrm{UFC} / \mathrm{mL})\end{array}$ \\
\hline 1 & $1,6 \times 10^{4}$ & $8,3 \times 10^{4}$ & $6,8 \times 10^{4}$ & $5,9 \times 10^{4}$ \\
\hline 2 & $5,6 \times 10^{7}$ & $1,1 \times 10^{7}$ & $2,7 \times 10^{7}$ & $2,9 \times 10^{5}$ \\
\hline
\end{tabular}

Limite máximo permitido: 3,0 x 105 UFC/mL (BRASIL, 2011).

Fonte: Dados da pesquisa.

Quanto às amostras de leites pasteurizados, levando-se em consideração a In $n^{\circ}$ 62/2011 (BRASIL, 2011) que estabelece o limite de contagem padrão em placas de 4,0 $\times 10^{4} \mathrm{UFC} / \mathrm{mL}$, pode-se observar na Tabela 3 que todas as amostras analisadas estão dentro dos padrões aceitáveis. 
Tabela 3. Contagem de coliformes totais em amostras de leite pasteurizados comercializados em dois estabelecimentos comerciais, em Ji - Paraná, Rondônia

\begin{tabular}{c|c|c|c|c}
\hline Supermercado & $\begin{array}{c}\text { Amostra 1 } \\
(\mathrm{UFC} / \mathrm{mL})\end{array}$ & $\begin{array}{c}\text { Amostra 2 } \\
(\mathrm{UFC} / \mathrm{mL})\end{array}$ & $\begin{array}{c}\text { Amostra 3 } \\
(\mathrm{UFC} / \mathrm{mL})\end{array}$ & $\begin{array}{c}\text { Amostra 4 } \\
(\mathrm{UFC} / \mathrm{mL})\end{array}$ \\
\hline 1 & $3,2 \times 10^{2}$ & $2,7 \times 10^{2}$ & $4,3 \times 10^{2}$ & $<1,0 \times 10^{1}$ \\
\hline 2 & $5,3 \times 10^{2}$ & $2,5 \times 10^{2}$ & $<1,0 \times 10^{1}$ & $<1,0 \times 10^{1}$ \\
\hline
\end{tabular}

Limite máximo permitido: 4,0 x 104 UFC/mL (BRASIL, 2011).

Fonte: Dados da pesquisa.

A Tabela 4 expõe os resultados obtidos nas análises dos queijos, onde, constatou-se que as amostras que não são submetidas a nenhum tipo de fiscalização foram as que apresentaram as maiores contagens de coliformes totais, seguida das amostras que passam pela fiscalização estadual, e federal.

Tabela 4: Contagem de coliformes totais em amostras de queijo minas frescal de acordo com o tipo de fiscalização em Ji-Paraná, Rondônia

\begin{tabular}{c|c|c|c}
\hline Amostras & $\begin{array}{c}\text { Fiscalização } \\
\text { Federal (UFC/g) }\end{array}$ & $\begin{array}{c}\text { Fiscalização } \\
\text { Estadual (UFC/g) }\end{array}$ & $\begin{array}{c}\text { Sem Fiscalização } \\
\text { (UFC/g) }\end{array}$ \\
\hline 1 & $1,5 \times 10^{2}$ & $4,6 \times 10^{3}$ & $6,8 \times 10^{5}$ \\
\hline 2 & $2,0 \times 10^{2}$ & $5,3 \times 10^{3}$ & $7,9 \times 10^{5}$ \\
\hline 3 & $1,6 \times 10^{2}$ & $7,0 \times 10^{3}$ & $1,1 \times 10^{6}$ \\
\hline 4 & $2,2 \times 10^{2}$ & $3,4 \times 10^{3}$ & $1,4 \times 10^{6}$ \\
\hline 5 & $3,1 \times 10^{2}$ & $8,3 \times 10^{2}$ & $6,0 \times 10^{6}$ \\
\hline
\end{tabular}

Limite máximo permitido: 1,0x10 $\mathrm{UFC} / \mathrm{mL}$ (BRASIL, 1996).

Fonte: Dados da pesquisa

\section{DISCUSSÃO}

Conforme observado, os resultados do presente estudo evidenciam que praticamente todas as amostras de carne moída analisadas apresentaram contaminação por coliformes totais, indicando assim, falhas durante seu processamento, visto que esse grupo de microrganismo é considerado um indicador das condições higiênico-sanitárias (MUNIZ; REIS; VIEIRA, 2017). Tais resultados podem estar relacionados com as condições precárias de higiene do local de processamento e/ou manipuladores, além de falhas na refrigeração, que favorecem a proliferação microbiana (Marchi et al., 2006).

Estudos disponíveis na literatura como o de Alves et al., (2011), Sousa et al., (2012), Nascimento et al., (2014) e Hangui et al., (2015), reportam dados 
semelhantes ao do presente estudo, pois descrevem a frequente presença de coliformes totais em amostras de carne moída de diferentes localidades do país.

A Tabela 2 demonstrou diferença na quantidade de contaminação entre as amostras de leite das duas propriedades rurais analisadas. A Instrução Normativa (IN) no 62/2011 do Ministério da Agricultura, Pecuária e Abastecimento (BRASIL, 2011), instrui que o leite cru deve ser mantido sob refrigeração após a ordenha, sendo preconizado o número de, no máximo, $3,0 \times 10^{5} \mathrm{UFC} / \mathrm{mL}$. Como pode-se observar, a propriedade rural um, a qual armazena o leite sob refrigeração, apresentou todas as amostras com valores dentro do preconizado.

Com relação à propriedade rural dois, o armazenamento do leite ocorre em tambores não refrigerados, prática essa, que se encontra fora da legislação. No entanto, não existe valores referenciais para coliformes totais em amostras não refrigeradas, contudo, se a avaliarmos de acordo com o valor referencial para aquelas refrigeradas, é possível verificar que apenas uma das amostras se encontra dentro do preconizado (BRASIL, 2011).

Portanto, os altos valores encontrados na propriedade dois, podem estar relacionados a ausência da refrigeração, tendo em vista que a refrigeração diminui a taxa de multiplicação bacteriana (HORST, 2006). Ainda, outros fatores que podem ser responsáveis por esse alto nível de contaminação por coliformes totais verificado na propriedade dois, são condições higiênicas inadequadas durante a ordenha, de limpeza dos equipamentos e dos utensílios (FROEDER, 1985).

Em um estudo no estado da Paraíba, PB, no qual foram avaliadas microbiologicamente amostras de leite cru de três produtores rurais, verificouse, elevada presença de bactérias mesófilas, coliformes totais e termotolerantes e Staphylococcus aureus em algumas amostras, sendo que o autor relaciona essa má qualidade do produto a ausência de refrigeração, uso de água não potável e má higienização na ordenha e dos equipamentos e utensílios utilizados (FREITAS; TRAVASSOS; MACIEL, 2013).

Em Viçosa, MG, um estudo avaliou a qualidade microbiológica como consequência das características da produção, sendo selecionadas 60 propriedades rurais, nas quais foram aplicados questionários aos produtores, dentre outras informações, observou-se que a maioria dos produtores relatou refrigerar o leite em tanques de imersão após a ordenha, o que demonstra que a região estudada já possuía esse procedimento bem estabelecido, sendo considerada uma importante ferramenta na garantia de qualidade do leite (NERO et al., 2009).

De acordo com Oliveira e colaboradores (2008) um leite de má qualidade não se recupera totalmente após o processo de pasteurização, já que cerca de $0,1 \%$ a $0,5 \%$ da contagem inicial de microrganismos patogênicos permanece viável. Entretanto, vale ressaltar que o grupo dos coliformes totais 
são sensíveis a temperatura do processo de pasteurização, o que evidencia, que se constatados no leite após o tratamento térmico uma contaminação pósprocessamento ocorreu (TAMANINI et al., 2007).

No presente estudo constatou-se que todas as amostras de leite pasteurizado analisadas estavam de acordo com os padrões estabelecidos para coliformes totais, o que também foi observado em outros estudos, como o de Luz et al. (2011) e Bernadino et al. (2009). Contudo, Tamanini et al. (2007) ao analisar 80 amostras de leites pasteurizados oriundas do norte do Paraná, constaram que $32,3 \%$ das mesmas apresentavam coliformes totais acima dos limites aceitos.

A presença de coliformes totais indica a necessidade de uma melhora nas condições higiênico-sanitárias, tanto para os produtores rurais, como para a indústria do leite pasteurizado. O constante incentivo para a adoção das boas práticas de produção por parte dos produtores tem como finalidade evitar contaminações (DURR, 2005).

Guido e colaboradores (2010) desenvolveram um estudo no município de Barbosa Ferraz (PR), no qual, buscou-se verificar a importância das boas práticas de produção por meio da realização de análises microbiológicas antes e após o treinamento de boas práticas, onde, constaram uma significativa redução da contaminação após a inserção do treinamento. Para Ferreira (2007) a qualidade do leite não está relacionada ao nível tecnológico presente na propriedade rural, mais sim com o manejo praticado pelo produtor.

Guido et al. (2010) salientaram que o acompanhamento constante dos produtores após receberem treinamento é fundamental, já que os mesmos não adotam imediatamente todos os procedimentos adequados, pois o aperfeiçoamento ocorre de forma gradativa.

Já na indústria, as boas práticas de fabricação são essenciais para a diminuição da contaminação (LOPES, 2007). As etapas posteriores à pasteurização (embalagem, transporte e comercialização) estão diretamente relacionadas à qualidade final do leite apresentado, sendo recomendado a realização das mesmas sob temperatura em torno dos $10^{\circ} \mathrm{C}$ (GONÇALVES; FRANCO, 1998).

A contaminação do leite após a pasteurização, na maioria das vezes está relacionada à inadequada limpeza dos equipamentos para embalagem, ou com a presença de microrganismos no ar, que consequentemente ocasiona a contaminação, levando a uma diminuição no tempo de vida do produto na prateleira (SANTOS; FONSECA, 2001).

Conforme apresentado na Tabela 4,100\% das amostras de queijos minas frescal sem fiscalização demonstraram estar irregular, levando-se em consideração a Portaria $\mathrm{n}^{\circ} 146 / 1996$ do Ministério da Agricultura, Pecuária e Abastecimento (MAPA) (BRASIL, 1996) que determina um limite máximo de $1,0 \times 10^{4} \mathrm{UFC} / \mathrm{mL}$, indicando assim, possíveis falhas durante seu preparo. 
Corroborando com o presente estudo, Ferreira et al. (2011), ao analisarem amostras caseiras sem nenhum tipo de fiscalização constataram que $70 \%$ das amostras estavam com nível de contaminação acima do permitido. Ainda, Salotti et al. (2006) verificaram que de 30 amostras com inspeção federal ou estadual $66,7 \%$ estavam fora do recomendado, enquanto que das 30 amostras produzidas de modo informal esse valor era de $83,3 \%$.

Okura e Moacir (2010), ao analisarem amostras de queijo minas frescal com e sem inspeção federal encontraram resultados que corroboram com presente estudo, pois verificaram que as amostras submetidas as controle federal apresentaram nível de contaminação inferior às amostras que não passaram por esse tipo de fiscalização.

\section{CONCLUSÃO}

A análise de coliformes totais revelou inadequada qualidade microbiológica nas amostras de carne moída, de leite cru não refrigerado e queijos produzidos sem fiscalização. Portanto, existe a necessidade de melhores condições de higiene no processamento da carne, bem como é fundamental a implantação de boas práticas de produção nas propriedades rurais para produção do leite, destacando-se a importância da utilização de tanque de refrigeração na propriedade dois. Cabe sinalizar a relevância de maior cautela no processo de pasteurização do leite, a fim de garantir um produto de qualidade ao consumidor. Por fim, quanto ao queijo minas frescal fica evidente a importância que a fiscalização federal exerce na qualidade do produto final.

\section{REFERÊNCIAS}

ALMEIDA, A.C.; SOUZA, R.M.; PINHO, L.; SOBRINHO, E.M.; SILVA, B.C.M. Determinação de perigos microbiológicos em carnes bovinas resfriadas provenientes de abates clandestinos e comércio ilegal. Acta veterinária Brasílica. v.4, n.4, p.278-285, 2010.

ALVES, V. C. et al. Coliformes e Salmonella spp. Em carne moída comercializada em Teresina, PI. Revista Brasileira de Medicina Veterinária. v. 33, n. 1, p. 32-36, 2011.

BERNADINO, Y.; UGUCCIONI, V. F.; SLVIERI, K.; RENSIS, C. M. V. B.; COSTA, M.R. qualidade físico-química e microbiológica do leite pasteurizado tipo c da região metropolitana de Londrina - PR. Revista do Instituto de Laticínio Cândido Tostes. V.369, n.64, p.13-18, 2009.

BRASIL. Ministério da Agricultura, Pecuária e Abastecimento. Instrução Normativa n.62 de 29 de dezembro de 2011. Diário Oficial da União, Brasília, seção 1, p.24, 2011.

CARVALHO, L.J.F.; SOUZA, R.L.N.; BRASIL, L.S.N.S.; SILVA, S.M.R.; JUNIOR, L.P.R.; FURTADO, C.R.S. Avaliação de dados microbiológicos de alimentos 
comercializados e consumidos na cidade de Belém do Pará. Centro Universitário do Estado do Pará, p.55-66, 2008.

DÜRR, J.W. Como produzir leite de alta qualidade. Brasília: Senar, 2005. 28 p

FAO - Food and Agriculture Organization of the United Nations. 2009. Disponível em: <http:/ / faostat.fao.org/. Acesso em dez. 2016.

FERREIRA, M.A. Controle de qualidade físico-químico em leite fluído. Brasília: Centro de Apoio ao Desenvolvimento Tecnológico da Universidade de Brasília (CDT/ UnB), 2007. 17 p.

FERREIRA, R. M. et al. Quantificação de coliformes totais e termotolerantes em queijo minas frescal artesanal. Pubvet. v. 5, n. 5, 2011.

FREITAS, W.C.; TRAVASSOS, A.E.R.; MACIEL, J.F. Avaliação microbiológica e físicoquímica de leite cru e queijo de coalho produzidos no estado da Paraíba. Revista Brasileira de Produtos Agroindustriais. v.15, n.1, p.35-42, 2013.

FROEDER, E.; PINHEIRO, A. J. R.; BRANDÃO S.C.C. Variação da qualidade microbiológica de leite cru tipo " $\mathrm{C}$ " da Região de Viçosa. Revista do Instituto de Laticínios Cândido Tostes. v. 40, n. 241, p. 55-68, 1985.

GEUS, J.A.M.; LIMA, J.A. Análise de Coliformes Totais e Fecais: Um comparativo entre técnicas oficiais VRBA e Petrifilm EC aplicados em uma indústria de carnes. In: II Encontro de Engenharia e Tecnologia dos Campos Gerais, 2006, Campos Gerais. ANAIS DO $2^{\circ}$ ENCONTRO DE ENGENHARIA E TECNOLOGIA DOS CAMPOS GERAIS. Ponta Grossa. 2006.

Gonçalves RMS; Franco RM. Determinação da carga microbiana em leite pasteurizado tipos " $\mathrm{B}$ " e " $\mathrm{C}$ ", comercializados na cidade do Rio de Janeiro. Revista Higiene Alimentar. v. 12, n. 53, p. 61-65, 1998.

GONÇALVES, R. M. S.; FRANCO, R. M. Determinação da carga microbiana em leite

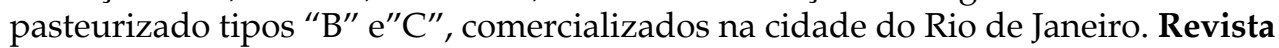
Higiene Alimentar. v. 12, n. 53, p. 61-65, 1998.

GUIDO, E.S.; SILVA, E.D.P.; SILVA, M.C.; TAKEUCHI, K.P.; DANESI, E.D.G. Uma abordagem da extensão universitária na melhoria da qualidade do leite na cadeia produtiva do município de Barbosa Ferraz (Paraná). Boletim do Centro de Pesquisa de Processamento de Alimentos. v. 28, n. 2, p. 303-312, 2010.

HANGUI, S. A. R. et al. Análise microbiológica da carne bovina moída comercializada na cidade de Anápolis, Goiás, Brasil. Revista Eletrônica de Farmácia. v. 7, n.2, p. 3038, 2015.

HORST, J. A. Impacto da refrigeração na Contagem Bacteriana do leite. In: MESQUITA, A.J.; DURR, J.W.; COELHO, K.O. Perspectivas e avanços da qualidade do leite no Brasil. Goiânia: talento, 2006, v. 1, p. 163-174. 
INSTITUTO BRASILEIRO DE GEOGRAFIA E ESTATÍSTICA - IBGE. Indicadores IBGE: Estatística da produção pecuária. 2017. Disponível em: < ftp:/ / ftp.ibge. gov.br/Producao_Pecuaria/Fasciculo_Indicadores_IBGE/abate-leite-couroovos_201701caderno.pdf> Acesso em: set. 2017.

INSTITUTO BRASILEIRO DE GEOGRAFIA E ESTATÍSTICA - IBGE- Pesquisa Agrícola Municipal (PAM) e Pesquisa da Pecuária Municipal (PPM). Disponível em: <http://www.ibge.gov.br>. Acesso em: jun. 2017.

LOPES, R.L.T. Fontes de contaminação de alimentos. Belo Horizonte: Fundação Centro Tecnológico de Minas Gerais (CETEC), 2007. 26 p.

LUZ, D.F. et al. Avaliação microbiológica em leite pasteurizado e cru refrigerado de produtores da região do Alto Pantanal Sul-Mato-Grossense. Revista Agrarian. v.4, n.14, p.367-374, 2011.

MAIA, M. B. R.; ALBUQUERQUE, E. S.; LEMOS, M. M.; SOUZA, D. B.; FILHO, T. A. S. Assistência técnica e extensão rural aos produtores de Economia familiar na cadeia produtiva do agronegócio leite no estado de Rondônia. Congresso da Sociedade Brasileira de Economia, Administração e Sociologia Rural. 48., 2010, Campo Grande. p. 21. Anais eletrônicos. Campo Grande, MS, 2010.

MARCHI, P.G.F. Estudo comparativo do estado de conservação de carne moída através de métodos Microbiológicos e Físico-químicos. 90f. Dissertação (Mestrado em Medicina Veterinária) - Curso de Medicina Veterinária, Faculdade de Ciências Agrárias e Veterinária, UNESP, Jaboticabal, 2006.

MATOS, V.S.R. et al. Perfil sanitário da carne bovina in natura comercializada em supermercados. Revista do Instituto Adolfo Lutz. v. 71, n. 1, p. 187-192, 2012

MUNIZ, C.M.; REIS, R.B.S.; VIEIRA, V.F. Coliformes totais e Escherichia coli em polpas de frutas comercializadas no Sudoeste da Bahia. Id on Line Revista Multidisciplinar e de Psicologia. v. 11, n. 35, p. 180-187, 2017.

NASCIMENTO, M. V. D. et al. Avaliação da qualidade microbiológica da carne moída fresca comercializada no mercado central em Campina Grande - PB. Revista Saúde e Ciência On line. v. 3, n. 1, p. 56-68, 2014.

NERO, L.A.; VIÇOSA, G. N.; PEREIRA, F.E.V. Qualidade microbiológica do leite determinada por características de produção. Ciência e Tecnologia de Alimentos. v. 29, n. 2, p. 386-390, 2009.

OKURA, M. H.; MOACIR, J. Avaliação das condições higiênico-sanitárias de queijos minas frescal produzidos com leite cru, leite pasteurizado e de queijo temperado em alguns municípios da região do Triângulo Mineiro. Revista do instituto de Laticínios Cândido Tostes. v. 375, n. 65, p. 33-42, 2010. 
OLIVEIRA, S.; SILVA, J.Á.; MACIEL, J.F.; AQUINO, J.S. Avaliação das condições higiênico-sanitárias de carne bovina comercializada em supermercados de João Pessoa. Alimentos e nutrição Araraquara. v. 19, n. 1, p. 61-66, 2008.

PERRY, K. S. P. Queijos: aspectos químicos, bioquímicos e microbiológicos. Química Nova. v. 27, n. 2, p. 293-300, 2004.

ROCHA, J. S.; BURITI, F. C . A.; SAAD, S. M . I. Condições de processamento e comercialização do queijo minas frescal. Arquivo Brasileiro de Medicina Veterinária e Zootecnia. v. 58, n. 2, p. 263-272, 2006.

SALOTTI, B., M. Qualidade microbiológica do queijo minas frescal comercializado no município de Jaboticabal, SP, Brasil. Arquivos do Instituto Biológico. v.73, n. 2, p. 171-175, 2006.

SANTOS, M. V.; FONSECA, L. F. L. Importância e efeito de bactérias psicrotróficas sobre a qualidade do leite. Revista Higiene Alimentar, São Paulo, v. 15, n. 82, p. 1319, 2001.

SILVA N.; JUNQUEIRA, V. C. A.; SILVEIRA, N. F. A.; TANIWAKI, M. H.; SANTOS, R. F. S.; GOMES, R. A. R. Manual de métodos de análise microbiológica de alimentos e água. 4, ed, São Paulo, Varela, 2010.

SOUSA, T. M.; NETO, A. C.; HERNANDES, T.; SOUTO, P. C. S. Microrganimos patogênicos e indicadores de condições higiênico-sanitária em carnes moída comercializada na cidade de Barra do Garças, MT. Acta Veterinaria Brasilica. v. 6, n. 2, p. 124-130, 2012.

TAMANINI, R. et al. Avaliação da qualidade microbiológica e dos parâmetros enzimáticos da pasteurização de leite tipo " $\mathrm{C}$ " produzido na região norte do Paraná. Semina: Ciências Agrárias. v. 28, n. 3, p. 449-454, 2007.

VIEIRA, K. P.; LEDESMA, M. M.; ROSA, C. M.; HASSEGAWA, R. H. Contaminação de queijo minas frescal por bactérias patogênicas: um risco à saúde. ConScientiane Saúde. v. 2, n. 7, p. 201-206, 2008. 